\title{
Magnetic Resonance Imaging findings of idipathic intracranial hypertension in a lymphoma patient
}

\section{Lenfoma tanılı hastada idiyopatik intrakranial hipertansiyonun Manyetik Rezonans Görüntüleme bulguları}

\author{
Burcu Şahin ${ }^{1}$, Elif Aktaş ${ }^{1}$, Ali Hakan Kaya ${ }^{2}$, Bilgin Kadri Arıbaş ${ }^{1}$ \\ ${ }^{1}$ Dr. Abdurrahman Yurtaslan Ankara Onkoloji Eğitim ve araştırma Hastanesi, Radyoloji Bölümü \\ ${ }^{2}$ Dr. Abdurrahman Yurtaslan Ankara Onkoloji Eğitim ve araştırma Hastanesi, Hematoloji Kliniği
}

Dergiye Ulaşma Tarihi: 25.04.2016 Dergiye Kabul Tarihi: 28.04.2016 Doi: 10.5505/aot.2017.19480

\begin{abstract}
ÖZET
İntrakranial hipertansiyonla komplike olan lenfoma tanılı 41 yaşındaki kadın hastanın MR bulgularını sunuyoruz. Bizim olgumuzda baş ağrısı ve görme bulanıklı̆̆ olması üzerine yapılan göz muayenesinde papil ödemle birlikte normal görme keskinliği saptanmıştır. Kranial ve orbita MRG sinde empty sella, optik sinirde tortiozite, skleral düzleşme, optik disk düzeylerinde protrüzyon, optik sinir etrafında artmış BOS izlenmiştir. MR venografisinde sağ sigmoid sinüste fokal bir alanda sinyal kaybı izlenmiş olup tromboza ait olabileceği düşünülmüştür. Olgumuzun MR bulguları eşliğinde intrakranial hipertansiyonun MR bulgularını sunmayı amaçladık.
\end{abstract}

Anahtar Kelimeler: intrakraniyal, hipertansiyon, psödotümör serebri, manyetik rezonans görüntüleme

\begin{abstract}
We herein report MR findings in a case of lymphoma complicated with intracranial hypertension in a 41 year old woman. Our patient presented with headache and blurred vision. Ophthalmic examination revealed normal visual acuity (20/20) in both eyes with papilledema. We saw empty sella, optic nerve tortuosity, scleral flattening, optic nerve head protrusion, increased perioptic cerebrospinal fluid on brain and orbit magnetic resonance imaging. Magnetic resonance venography of the brain showed lack of flow in the right sigmoid dural sinuses suggestive of venous thrombosis. We aim to present intracranial hypertension MR features with our patient's MRI findings.

Keywords: intracranial, hypertension, pseudotumor cerebri, magnetic resonance imaging
\end{abstract}

\section{Giriş:}

İdiopatik intrakranial hipertansiyon(İ̈H) beyin omurilik sıvı basıncının artışı ile karakterize sebebi bilinmeyen bir hastalıktır. Psödotümör serebri olarak da bilinmektedir. Genellikle doğurganlık çağındaki obez kadınlarda görülmektedir. 15-44 yaş arasındaki kadınlarda 3,5/100.000 oranında görülürken normal kilosunun \%20 sinden fazla kiloya sahip 20-44 yaş arası kadınların 100000'inin 19'unda görülmektedir(1). Başağrısı (\%94), pulsatil tinnitus(\%58), fotopsi(\%54), retrobulber ağr1 $(\% 44)$, geçiçi göz kararması $(\% 68)$ ve geçiçi görme kaybına (\%30) neden olabilmektedir. Altınc kranial sinir parezisine ve papil ödeme bağlı çift görme (\%38) ortaya çıkabilir(1). Bu olgumuzda lenfoma tanısı olan papil ödem ve başağnısı nedeniyle $\dot{\mathrm{I}} H \mathrm{H}$ düşünülen hastanın manyetik rezonans (MR) görüntüleme bulgularını sunmayı amaçladık.

\section{Olgu Sunumu:}

Kilo kaybı ve boynunda ele gelen şişlik nedeni ile hastaneye başvuran kırk bir yaşında kadın olguya yapılan servikal lenf bezi biyopsisi sonucu periferal $\mathrm{T}$ hücreli lenfoma tanıs1 konmuştur. Tedavi altında iken tümör lizis sendromu gelişmiş, tümör lizis sendromu tedavisi sonrası gelişen görme bulanıklığ 1 ve baş ağrısı semptomları nedeniyle yapılan göz muayenesinde papil ödemi tespit edilmiştir. Diğer nörolojik muayene bulguları normal bulunmuş olupkranial MRG incelemesinde sella boyutlarının arttığı ve suprasellar sisternin sella içerisine uzanım gösterdiği tespit 
edilmiştir (Resim 1). Sağ sigmoid sinüste sinyal void kaybı izlenmiştir (Resim 2). Orbita MR incelemesinde her iki optik sinir etrafinda artmış BOS'a ait sinyal izlenmiştir. Her iki optik sinir tortiyozite göstermekteydi (Resim 3). Her iki bulbus okuli posteriorunda düzleşme ve optik disk düzeylerinde solda belirgin olmak üzere protrüzyon izlenmiştir. MR venografisinde sağ sigmoid sinüste fokal bir alanda sinyal kaybi izlenmiş olup tromboza ait olabileceği düşünülmüştür (Resim 4).

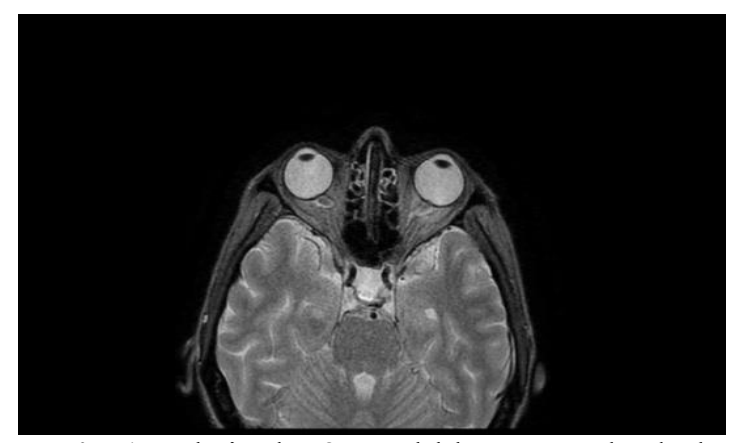

Resim1: Aksiyel T2 ağırlıklı görüntülerde her iki optik sinir etrafında artmıs Bos, tortiozite gösteren optik sinirler, optik disk düzeylerinde solda belirgin olmak üzere protrüzyon izlenmiştir.

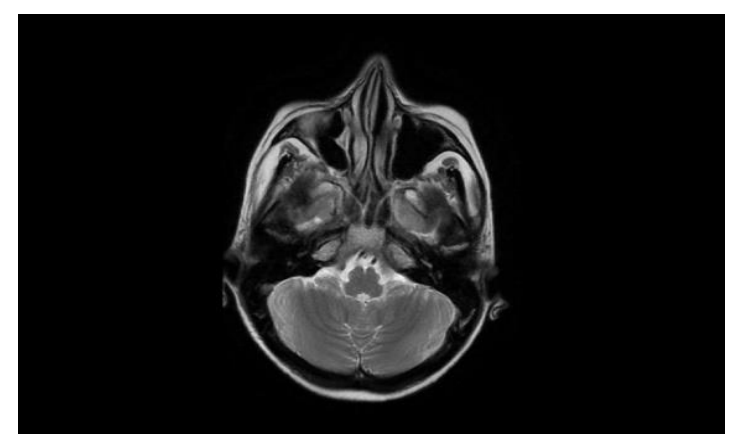

Resim 2: Aksiyel T2 ağırlıklı görüntülerde sağ sigmoid sinuste sinyal void kaybı izlenmektedir.

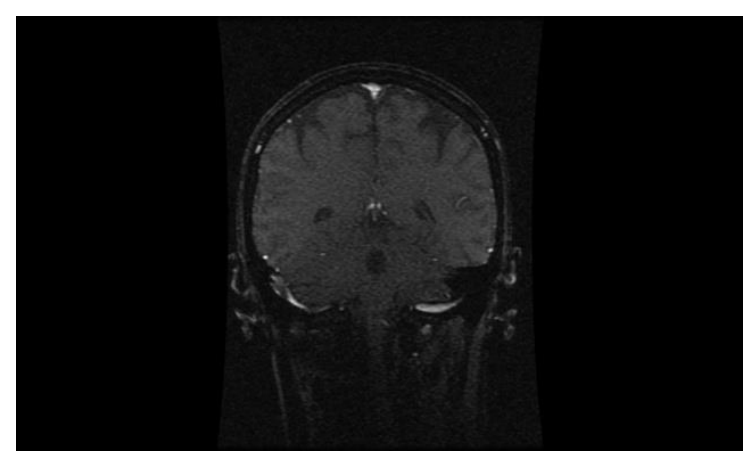

Resim 3: MR venografide sağ sigmoid sinüste fokal sinyal kaybı izlenmektedir.

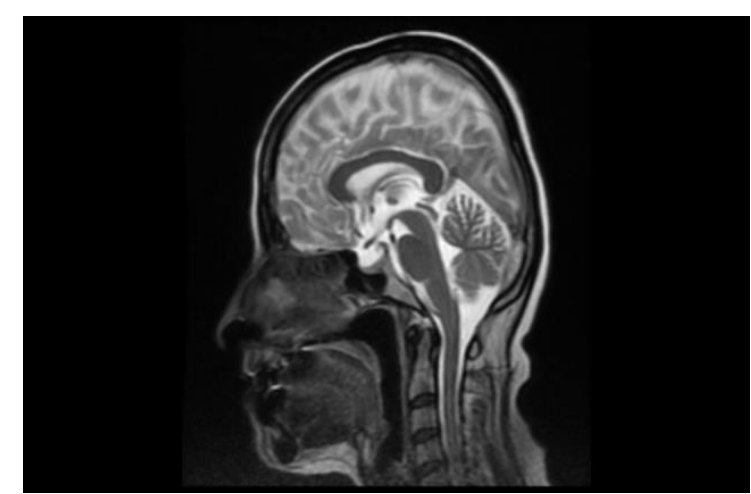

Resim 4: Sagittal T2 ağırlıklı görüntülerde sella anterior-posterior çapında artma $(18 \mathrm{~mm})$ ve suprasellar sisternin sellaya uzanımı görülmektedir.

\section{Tartıșma:}

İntrakranial hipertansiyon, intrakranial basınc1 artıran patolojiler nedeniyle ortaya çıkabilir. Venöz tromboz, hemorajik inme gibi durumlara sekonder beyin kan volümunun artmas1, intrakranial kitle ve serebral ödeme sekonder beyin volümünün artması ile koroid pleksus tümörü ve BOS akımına engel olan tümörlere sekonder BOS volümünün artmasına neden olan durumlar intrakranial hipertansiyona neden olabilir $(1,2)$. Bizim olgumuzda sinüs trombozu kan volümünün artmasina sebep olarak intrakranial hipertansiyon bulgularına neden olmuş olabilir. Aynı zamanda hastanın tümör lizis sendromunda olması da sıvı yükünü artırarak bu bulgulara neden olabilir. Ĕger etyolojiyi açılayacak bir neden bulunamazsa IIIH tanısı konulur. İ̈H bir ekartasyon tanısıdır. İIH'li hastaların yaklaşık \%90'ında MR venografisinde transvers sinüs stenozu(TSS) tespit edilmektedir. Ancak TSS'nin İHH'nin bir nedeni mi yoksa bir sonucu mu olduğu kesinlik kazanmamıştır(3). İntrakranial hipertansiyonlu hastalarda MR'da posterior sklerada düzleşme $(\% 80)$, boş sella(\%70), perioptik subaraknoid boşlukta genişleme $(\% 50)$, prelaminar optik sinirin kontrastlanması $(\% 45)$, optik sinirde vertikal tortiyozite $(\% 40)$ ve prelaminer optik sinirin intraoküler protrüzyonu (\%30) görülebilir. Bu bulgular IIIH'de daha s1k görülmektedir(2,4). Brodsky ve Vaphiades yaptıkları çalışmada 20 İIH tanısı olan hastada posterior sklerada düzleşme, prelaminer optik sinirde kontrastlanma, perioptik subaraknoid boşlukta genişleme, prelaminer optik sinirin intraoküler protrüzyonu, orbital optik sinirde vertikal tortiyozite ve boş sella görünümü kontrol grubuna göre anlamlı yüksek 
bulunmuştur (5). Agid ve arkadaşları tarafindan 30 İïH'li hastada yapılan çalışmada yukarıda tanımlanan bulgular kontrol grubuna göre anlamlı yüksek bulunmuştur (6). Maralani ve Agid tarafından yapılan iki ayrı çalışmada posterior globdaki düzleşmenin İHH için yüksek spesifite gösterdiği saptanmıştır $(6,7)$.

\section{Sonuç:}

İdyopatik intrakranial hipertansiyon için yapılan görüntüleme yöntemlerinin asıl amacı intrakranial hipertansiyona neden olabilecek patolojileri dışlamaktır. Ancak İHH'de boş

\section{Referanslar}

1.Wall M. Idiopathic intracranial hypertension. NeurolClin. 2010;28:593-617.

2.Saindane AM, Bruce BB, Riggeal BD, Newman NJ, Biousse V. Association of MRI findings and visual outcome in idiopathic intracranial hypertension. AJR Am J Roentgenol. 2013;201:412-8.

3.Maralani PJ, Hassanlou M, Torres C, Chakraborty S, Kingstone M, Patel V et al. Accuracy of brain imaging in the diagnosis of idiopathic intracranial hypertension. Clinical radiology. 2012; 67: 656-663.

4.Skyrman S, Fytagoridis A, Andresen M, Bartek J Jr. Idiopathic intracranial hypertension and transverse sinus stenoses. BMJ Case Rep. 2013; 28:1-3. sella, posterior glob düzleşmesi, optik sinirde tortiyozite ve optik sinir kılıfında genişleme gibi bazı non-spesifik görüntüleme bulguları olduğu çeşitli literatürlerde tanımlanmıştır. Bu bulguların olması İHH için diagnostik değildir ancak papil ödem gibi diğer nörolojik bulgulara eşlik etmesi halinde tanıyı desteklemektedir. Diğer bir deyişle klinik bulgularla İIHH düşünülen olgularda görüntüleme bulgularının negatif olması İHH tanısını dişlamaz ancak görüntüleme bulgularının pozitif olması tanıyı destekler.

\section{Çıkar Çatışması: Yok}

5.Brodsky MC, Vaphiades M. Magnetic resonance imaging in pseudotumor cerebri. Ophthalmology 1998; 105:1686-1693.

6.Agid R, Farb RI, Willinsky RA, MikulisDJ, Tomlinson G. Idiopathic intracranial hypertension: the validity of cross-sectional neuroimaging signs. Neuroradiology 2006; 48:521-527.

7.Maralani PJ, Hassanlou M, Torres C, et al. Accuracy of brain imaging in the diagnosis of idiopathic intracranial hypertension. ClinRadiol 2012; 67:656-663. 